\title{
Climate extremes in multi-model simulations of stratospheric aerosol and marine cloud brightening climate engineering
}

\author{
V. N. Aswathy ${ }^{1}$, O. Boucher ${ }^{2}$, M. Quaas ${ }^{3}$, U. Niemeier ${ }^{4}$, H. Muri ${ }^{5}$, J. Mülmenstädt ${ }^{1}$, and J. Quaas ${ }^{1}$ \\ ${ }^{1}$ Institute for Meteorology, Universität Leipzig, Leipzig, Germany \\ ${ }^{2}$ Laboratoire de Météorologie Dynamique / IPSL / CNRS, Université Pierre et Marie Curie, Paris, France \\ ${ }^{3}$ Department of Economics, Christian-Albrechts-Universität zu Kiel, Kiel, Germany \\ ${ }^{4}$ Atmosphäre im Erdsystem, Max-Planck-Institut für Meteorologie, Hamburg, Germany \\ ${ }^{5}$ Department of Geosciences, University of Oslo, Oslo, Norway \\ Correspondence to: J. Quaas (johannes.quaas@uni-leipzig.de)
}

Received: 2 December 2014 - Published in Atmos. Chem. Phys. Discuss.: 22 December 2014

Revised: 31 May 2015 - Accepted: 5 August 2015 - Published: 27 August 2015

\begin{abstract}
Simulations from a multi-model ensemble for the RCP4.5 climate change scenario for the 21 st century, and for two solar radiation management (SRM) schemes (stratospheric sulfate injection (G3), SULF and marine cloud brightening by sea salt emission SALT) have been analysed in terms of changes in the mean and extremes of surface air temperature and precipitation. The climate engineering and termination periods are investigated. During the climate engineering period, both schemes, as intended, offset temperature increases by about $60 \%$ globally, but are more effective in the low latitudes and exhibit some residual warming in the Arctic (especially in the case of SALT which is only applied in the low latitudes). In both climate engineering scenarios, extreme temperature changes are similar to the mean temperature changes over much of the globe. The exceptions are the mid- and high latitudes in the Northern Hemisphere, where high temperatures (90th percentile of the distribution) of the climate engineering period compared to RCP4.5 control period rise less than the mean, and cold temperatures (10th percentile), much more than the mean. This aspect of the SRM schemes is also reflected in simulated reduction in the frost day frequency of occurrence for both schemes. However, summer day frequency of occurrence increases less in the SALT experiment than the SULF experiment, especially over the tropics. Precipitation extremes in the two SRM scenarios act differently - the SULF experiment more effectively mitigates extreme precipitation increases over land compared to the SALT experiment. A reduction in dry spell occurrence over land is observed in the SALT experiment. The SULF
\end{abstract}

experiment has a slight increase in the length of dry spells. A strong termination effect is found for the two climate engineering schemes, with large temperature increases especially in the Arctic. Globally, SULF is more effective in reducing extreme temperature increases over land than SALT. Extreme precipitation increases over land is also more reduced in SULF than the SALT experiment. However, globally SALT decreases the frequency of dry spell length and reduces the occurrence of hot days compared to SULF.

\section{Introduction}

Observed and projected global warming due to continuously increasing greenhouse gas emissions has driven research focusing on the mitigation of greenhouse gas emissions and on adaptation to climate change, and lately on alternative methods to counterbalance global warming. Climate engineering (or geoengineering) has been proposed as a means to counteract global warming in the case mitigation efforts prove insufficient or climate change becomes catastrophic (e.g. Crutzen, 2006; Schmidt et al., 2012). There are many proposed methods of climate engineering, which can be classified into two major categories, namely solar radiation management (SRM) and carbon dioxide removal (CDR). Solar radiation management aims to reduce solar radiation absorbed by the Earth system by increasing its albedo.

Several SRM techniques have been being discussed; among them, stratospheric sulfate aerosol injection has been 
suggested to be the most feasible and least expensive (Lenton and Vaughan, 2009; Robock et al., 2009). SRM through marine cloud brightening is another technique, first proposed by Latham (1990). A number of single model studies have addressed both SRM techniques (Latham, 2002; Robock et al., 2008; Jones et al., 2009, 2010; Niemeier et al., 2013). Different experiment designs, however, hinder direct model-tomodel comparisons (Kravitz et al., 2011). To answer the questions raised in independent studies, a suite of standardised climate modelling experiments has been performed within a coordinated framework, known as the Geoengineering Model Intercomparison Project (GeoMIP, Kravitz et al., 2013). GeoMIP consists of four solar climate engineering experiments namely G1, G2, G3 and G4, in which the G3 and G4 experiments investigate the effects of stratospheric sulfate aerosol injections. The GeoMIP G3 experiment is analysed in our study. Similarly, a first multi-model approach with a standard experimental setup to study sea salt climate engineering (SSCE), i.e. marine cloud brightening, has been performed within the Implications and risks of engineering solar radiation to limit climate change (IMPLICC) project (Alterskjaer et al., 2013).

The objective of this paper is to examine multi-model simulation results in terms of changes in mean and extreme temperature and precipitation as a consequence of reducing incoming solar radiation at the surface by these two different SRM techniques.

Kharin et al. (2007) found that the changes in temperature extremes can be expected to generally follow changes in mean temperatures in many parts of the world. However, especially over the mid- and high latitudes, temperature extremes may show larger relative changes, and over land, models show an increase in temperature variability in a warming climate (Kharin and Zwiers, 2005). According to the recent assessment report of the Intergovernmental Panel on Climate Change (IPCC), there will be more hot and fewer cold temperature extremes and a likely increase in precipitation extremes in a warmer world (Collins et al., 2013).

In this study, we compare the impact of stratospheric sulfate injection and sea salt climate engineering on changes in the means and extremes of climate parameters. For stratospheric sulphate injection, we use the GeoMIP G3 experiment, in which stratospheric aerosols are added gradually to background levels following the Representative Concentration Pathway 4.5 scenario (RCP4.5), to balance the anthropogenic forcing and to keep the global mean surface temperature nearly constant (Kravitz et al., 2011). The IMPLICC G3-SSCE is based on the GeoMIP G3 experiment, but sea salt emissions (by which marine cloud brightness is altered) are used rather than stratospheric aerosols to compensate for anthropogenic forcing. Following Niemeier et al. (2013), we denote the G3 experiment (stratospheric sulfur injection) as SULF and G3-SSCE (marine cloud brightening by sea salt emission) as SALT.
The SULF experiment exerts its forcing globally, whilst the SALT scheme is employed only over tropical oceans between $30^{\circ} \mathrm{S}$ and $30^{\circ} \mathrm{N}$.

The climatic properties of the SULF and SALT experiments have been presented in previous studies. These focused mainly on the temporal and spatial distributions of climate engineering effects on the mean climate (Schmidt et al., 2012; Alterskjaer et al., 2013; Kravitz et al., 2013; Muri et al., 2015). Schmidt et al. (2012) studied the responses of four Earth system models to climate engineering in the G1 scenario. In this scenario, the radiative forcing from the quadrupling of $\mathrm{CO}_{2}$ is balanced by reducing the solar constant. Alterskjaer et al. (2013) investigated the simulation of SALT. Their results showed that a sufficiently strong application of SALT led to the compensation of the global annual mean warming by RCP4.5 in all models. The models showed a suppression of evaporation and reduced precipitation over lowlatitude oceans and vice versa over low-latitude land regions. Kravitz et al. (2013) summarised the current knowledge as gained from the GeoMIP simulations and remaining research gaps. They found that none of the participating models could maintain both global-mean temperature and precipitation to preindustrial levels from a high $\mathrm{CO}_{2}$ scenario, in agreement with theoretical considerations.

Presently, very few studies address the impact of climate engineering on extreme events and hardly any research has yet focused on more realistic scenarios. Recent studies by Tilmes et al. (2013) and Curry et al. (2014) examined climate extremes in the multi-model climate engineering experiment (G1). The study by Tilmes et al. (2013) mainly focuses on the hydrological impact of the forcing as applied in the G1 experiment. As part of their study, they also analyse the upper-percentile shifts in the annual and seasonal precipitation from monthly averaged model output in both $\mathrm{G} 1$ and abrupt $4 \times \mathrm{CO}_{2}$ experiments relative to the preindustrial control state. In the tropics, the G1 experiment tends to reduce heavy precipitation intensity compared to the control simulation. Their results showed a weakening of the hydrological cycle under the G1 experiment.

Curry et al. (2014) investigated the temperature and precipitation extremes in the G1 scenario. They were found to be smaller than in the abrupt $4 \times \mathrm{CO}_{2}$ scenario, but significantly different from preindustrial conditions. A probability density function analysis of standardised monthly surface temperature exhibited an extension of the high-end tail over land and of the low-end tail over ocean, while the precipitation distribution was shown to shift to drier conditions. The strong heating of northern high latitudes as simulated under $4 \times \mathrm{CO}_{2}$ is largely offset by the G1 scenario. However, significant warming was found to remain, especially for daily minimum temperature compared to daily maximum temperature for the given time period. The changes in temperature extremes were found to be more effectively reduced compared to precipitation extremes. 
The climate extreme indices used in this study are defined in Table 1 (see Methods described in Sect. 2). Details of the experiments considered in the study and the models and methods used are described in Sect. 2. In Sect. 3, we discuss the geographical distribution of the climate extremes under the two climate engineering scenarios. Annual and seasonal variations of the extremes and the effect of termination on the extremes are discussed in the corresponding subsections of Sect. 3. In Sect. 4, we discuss the implication of our results and present the conclusions.

\section{Data and methodology}

Results from three Earth system models (ESM) were available for the analysis. The models are the Max Planck Institute's ESM (MPI-ESM; Giorgetta et al., 2013), the Norwegian Climate Centre ESM (NorESM; Bentsen et al., 2013) and the Institute Pierre Simon Laplace fifth-generation Coupled Model (IPSL-CM5; Dufresne et al., 2013). ECHAM6 (European Centre for Medium-range Weather Forecasts (ECMWF) - HAMburg version model), the atmospheric component of the MPI-ESM lower resolution model (MPIESM-LR), runs at a resolution of T63 (triangular truncation at wave number 63 , corresponding to approximately $1.9^{\circ} \times 1.9^{\circ}$ ) with 47 vertical levels. The Norwegian Earth System Model 1 medium resolution (NorESM1-M) atmospheric component CAM4-OSLO has a resolution of $1.9^{\circ} \times 2.5^{\circ}$ with 26 vertical levels, whilst LMDZ, the atmosphere in the IPSL Earth System Model for the fifth IPCC report has a low resolution (ISPL-CM5A-LR), running at a resolution of $1.9^{\circ} \times 3.75^{\circ}$ with 39 vertical levels. The advantage of using models of such different components and resolutions is that the results from the different models are expected to span a large part of the uncertainty range of the results (Kravitz et al., 2013).

The aim of the climate engineering experiments is to balance the excess radiative forcing to remain at 2020 levels implied by the anthropogenic climate change in the RCP4.5 post-2020. ${ }^{1}$ The experiments SALT and SULF follow the experiment design as given in Kravitz et al. (2011). For the SALT-only NorESM included sea salt emissions. The other two models prescribed the aerosols as calculated from NorESM (Alterskjaer et al., 2013). In the SULF simulation, the aerosol effects on radiation is included in the models via their optical properties (Niemeier et al., 2013). This is achieved by prescribing aerosol optical depth (AOD) and effective radius, which were calculated in previous simulations with an aerosol microphysical model ECHAM5-HAM (Niemeier et al., 2011; Niemeier and Timmreck, 2015). This approach allows an impact of the aerosol heating on the dynamic of the ESM, while the feedback process of the dynamic on the aerosols was only included in the previous sim-

\footnotetext{
${ }^{1} \mathrm{RCP} 4.5$ is a scenario that stabilises radiative forcing at $4.5 \mathrm{~W} \mathrm{~m}^{-2}$ in the year 2100 (Taylor et al., 2012).
}

ulations with ECHAM5-HAM. For both experiments, these are done increasingly in time, i.e. for 50 years from 2020 to 2070 in order to reflect enough solar radiation to balance the increasing anthropogenic greenhouse effect. An additional 20 year extension of the simulation until 2090 is performed to explore the effect of the abrupt cessation of the SRM, which is referred to as the "termination effect" (Jones et al., 2013).

In the NorESM SULF experiment, an implementation inaccuracy leads to an overly large radiative effect in the terrestrial spectrum, by up to 0.5 to $1 \mathrm{Wm}^{-2}$ in the last decade of the geoengineering. The consequence of a too high LW absorption by the aerosols in the stratosphere is moderately strong radiative warming in the stratosphere. This means more $\mathrm{SO}_{2}$ was needed in order to achieve the desired effect in NorESM1-M SULF.

In the SALT experiment, the globally averaged radiative forcing in RCP4.5 relative to the year 2020 is balanced via marine cloud brightening (MCB) by increasing injections of sea salt into the tropical marine atmospheric boundary layer (Alterskjaer et al., 2013). The seeding region chosen for the experiment extends between $30^{\circ} \mathrm{N}$ and $30^{\circ} \mathrm{S}$ over ocean. Seeding regions were chosen based on an earlier study by Alterskjær et al. (2012). For a detailed description of the SALT results and experiment design the reader is referred to Alterskjaer et al. (2013); Muri et al. (2015).

The MPI-ESM performed three realisations for both SULF and SALT experiments. The NorESM1-M performed two realisations for both experiment, while IPSL-CM5A has one realisation for each experiment. Based on the time period chosen for analysis, firstly we compute the model statistics for each ensemble member for the models where more than one are available, and then consider the multi-model average. The multi-model mean results are given an equal weight for all three models (i.e. first taking the ensemble-average for the models where more than one ensemble member was available). Prior to all calculations, all the three models ensembles are re-gridded to a common resolution, choosing the lowest of the model resolutions of $1.9^{\circ} \times 3.75^{\circ}$ (IPSL-CM5A-LR resolution).

\subsection{Climate extreme analysis}

In this study, climate extremes are defined by the lower and upper percentiles of the temporal distribution at each grid point and a set of indices defined by the Expert Team of Climate Change Detection and Indices (ETCCDI, Sillmann et al., 2013).

The daily average model output is analysed for 30-year periods, except when analysing the termination effect, in which case a 20-year period is assessed. For the annual mean analysis, the data from which the extremes are drawn covers 10950 days and for termination it is 7300 days at each model grid point.

Climate extremes are defined by the 90th and 10th percentile of the time series of near-surface air temperature (T90 
Table 1. Climate extreme indices.

\begin{tabular}{|c|c|c|c|}
\hline Index & Description & Index definition & Units \\
\hline T90, T99 / P90, P99 & 90th/99th percentile & $\begin{array}{l}\text { 90th/99th percentiles of the temporal distribution for } \\
\text { given time period from temperature and precipitation }\end{array}$ & $\mathrm{mm}_{\text {day }}-1 /{ }^{\circ} \mathrm{C}$ \\
\hline $\mathrm{T} 10 / \mathrm{T} 1$ & 10th/1st percentile & $\begin{array}{l}\text { 10th } / 1 \text { st percentiles of the temporal distribution for } \\
\text { given time period from temperature }\end{array}$ & ${ }^{\circ} \mathrm{C}$ \\
\hline CDD & Consecutive dry days & $\begin{array}{l}\text { Number of consecutive days when precipitation rate } \\
<1 \mathrm{~mm} \mathrm{day}^{-1} \text { in given time period }\end{array}$ & days $\mathrm{yr}^{-1}$ \\
\hline FD & Frost days & Number of days per time period when $\mathrm{TN}<0^{\circ} \mathrm{C}$ & days $\mathrm{yr}^{-1}$ \\
\hline SU & Summer days & Number of days per time period when $\mathrm{TX}>25^{\circ} \mathrm{C}$ & days $y^{-1}$ \\
\hline
\end{tabular}

and T10 respectively) and 90th percentile of surface precipitation flux (P90) at individual model grid points. We also investigate higher percentiles (eg 99th), but this only as a global land or ocean average (as shown in Table 2).

The additional climate extreme indices used in this study are the frequencies of occurrence of summer days (SU), frost days (FD) and the maximum count of consecutive dry days (CDD) in the period. These are computed from daily maximum temperature, daily minimum temperature and precipitation, respectively. Data for daily maximum (TX) and daily minimum $(\mathrm{TN})$ temperature are directly provided from the models. Frost day (FD) represents the number of days when $\mathrm{TN}<0^{\circ} \mathrm{C}$ and summer days (SU) define the number of days when $\mathrm{TX}>25^{\circ} \mathrm{C}$ for the given time period (usually 3 decades in our analysis). The consecutive dry days (CDD) provides the largest number of consecutive days when daily precipitation is less than $1 \mathrm{~mm} \mathrm{day}^{-1}$ in the analysed time period. In Table 4 and Figs. 4, 5 and 6 the units for CDD, FD and SU are converted to days per year.

To assess the influence of climate engineering on a changing climate, for every climate extreme index analysis, the last 3 decades of climate engineering (2040 to 2069) are compared with the 3-decade average at the beginning of the RCP4.5 scenario simulation (2006 to 2035 , denoted as control period, CTL). The same analysis is conducted for the corresponding RCP4.5 scenario for the same time periods. In addition to the annual mean changes, we also investigate extreme events for different seasons namely, DecemberJanuary-February (DJF) and June-July-August (JJA), presented in Sect. 3.5.

To determine the effect of the abrupt cessation of climate engineering on extremes, the upper and lower percentiles of both temperature and precipitation for the 2 decades after termination, i.e. years 2070 to 2089 (referred to as 2070s), are compared to the last 2 decades of the climate engineering period (i.e. 2050 to 2069, represented as 2050s). A similar analysis is carried out for RCP4.5 as well in order to investigate the changes during the same time periods.

Both climate engineering techniques are compared with the RCP4.5 (2040 to 2069) period, and the values are given in Table 6.

\section{Results and discussion}

For reference, Tables 2, 3 and 5 show the changes in globally averaged values of mean and extreme (percentile-based method) values of temperature and precipitation and Table 4 shows the globally averaged mean values of the other extreme event indices (Sect. 3.3 and 3.4). As supplementary information, ensemble separated values for each model and for all scenarios are also provided, with the ensemble members showing relatively small variations between them.

The main aim of the climate engineering experiment is to keep the globally averaged top-of-the-atmosphere radiative forcing at the RCP4.5 2020 level, hence it does not fully constrain the regional climate characteristics (Curry et al., 2014). Niemeier et al. (2013) computed the shortwave (SW) and long-wave (LW) top-of-the-atmosphere (TOA) flux changes for the last decade of climate engineering minus the RCP4.5 (2015-2024) for the MPI-ESM. They found that the shortwave TOA change for the SALT experiment in the MPI-ESM was smaller than the one for SULF over both ocean and land (Fig. S1 in the Supplement). However, for the SALT experiment, TOA SW fluxes are slightly larger over ocean relative to land. The difference of the solar radiation flux between land and ocean in SALT reflects the more local nature of this SRM, since SALT is applied only over tropical oceans. The long-wave (LW) fluxes of both SRM schemes are similar, although the fluxes of the SULF experiment are slightly larger than the SALT experiment, except for all-sky conditions over land.

\subsection{Statistical significance}

To determine the robustness of the results, we compute statistical significance test for the mean and extreme changes. Statistical significance of the change in mean temperature is computed using a two-sided Student $t$ test. For the mean change in precipitation we use Kolmogorov-Smirnov test, since the test is non-parametric and make no assumptions about the probability distributions of the variable used (Conover, 1980).

The distribution of T90, T10, P90, SU, FD, and CDD is not sampled by the climate models (each ensemble member only 
Table 2. Change in temperature 2040 to 2069 minus the RCP4.5 control period (2006-2035).

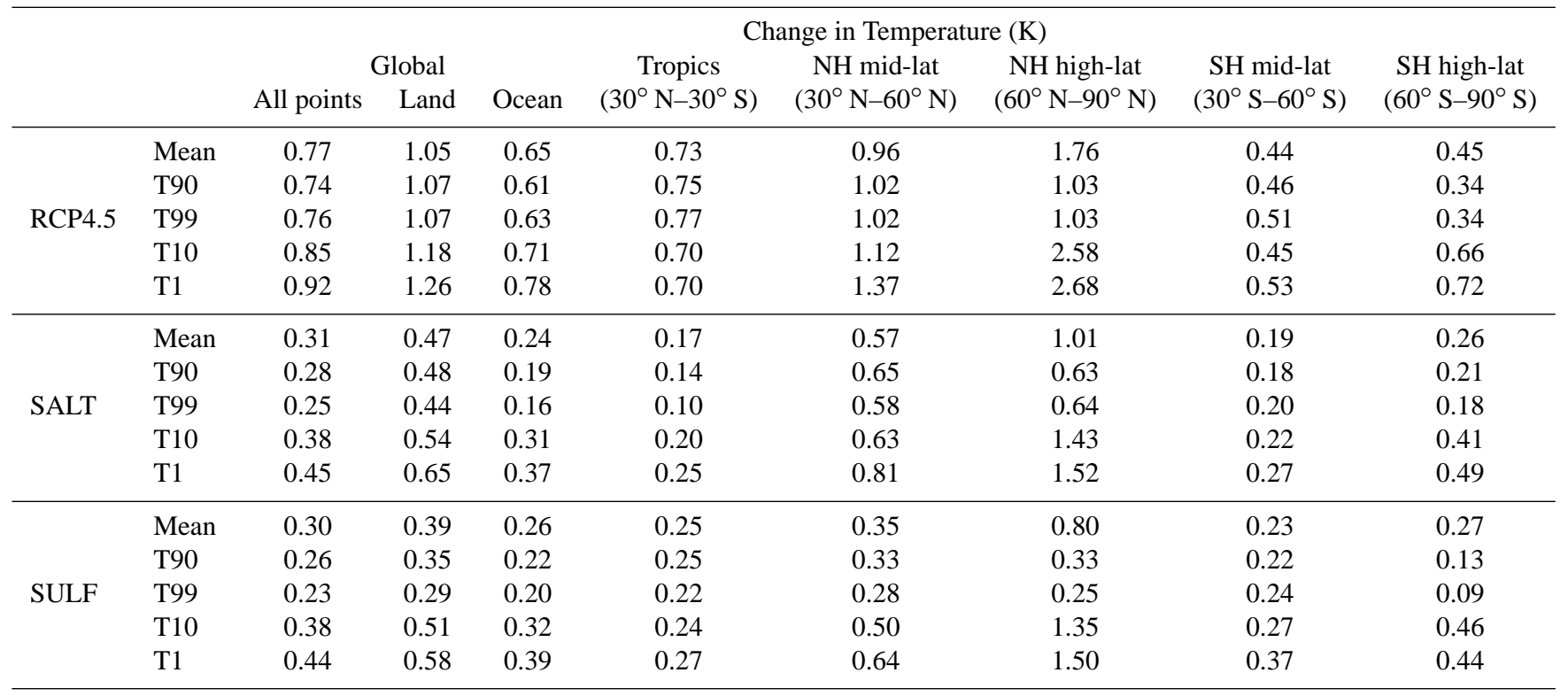

Table 3. Change in precipitation 2040 to 2069 with respect to the reference RCP4.5 2006-2035 period.

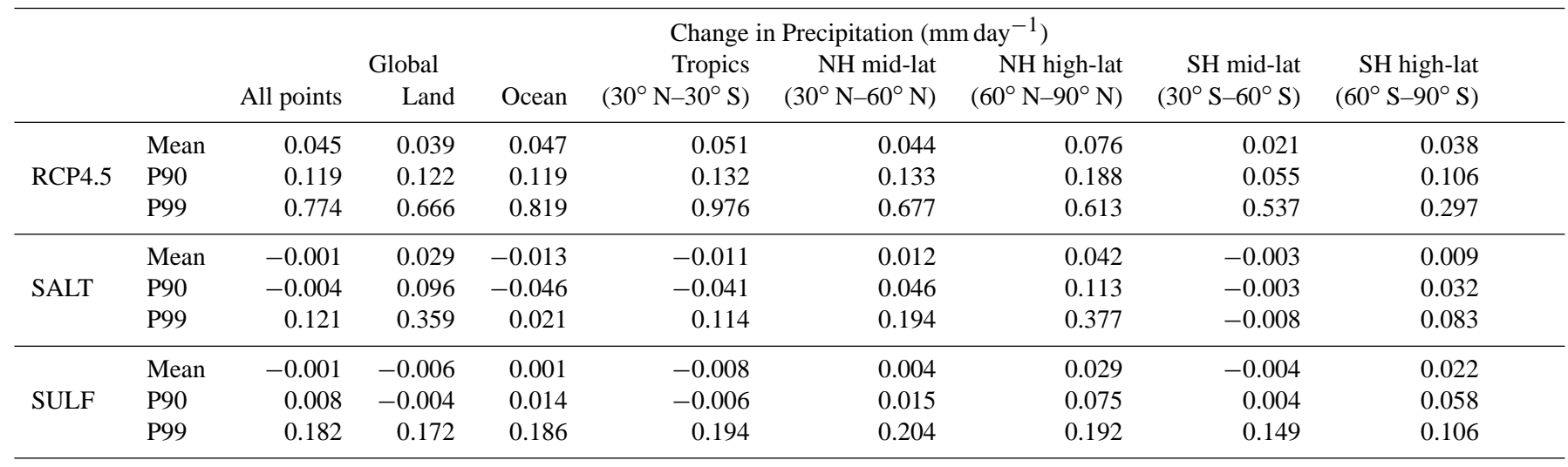

provides a single value). To estimate the distribution function of these variables, we use sampling with replacement ("bootstrapping", e.g. Efron and Tibshirani, 1998). In the case of T90 and T10, the distribution of daily mean temperature is sampled. In the case of P90, the distribution of daily accumulated rainfall is sampled. In the case of CDD, contiguous days with below-threshold precipitation $\left(<1 \mathrm{~mm} \mathrm{day}^{-1}\right)$ are indexed, and the set of indices is sampled; this procedure preserves the temporal autocorrelation of the precipitation distribution. In the case of summer (winter) days, a binomial distribution with probability $n / N$ is sampled, where $n$ is the number of summer (winter) days and $N$ is the total number of days in the model run. In all cases, 1000 samples of size $N$ are used. The distribution is calculated independently at each grid point.

Once the bootstrapped probability distribution function for each model run $i$ has been determined, the perturbed distri- bution $f_{i}(x)$ is compared to the reference distribution $g_{i}(x)$. The aim is to test the null hypothesis that $f_{i}(x)$ and $g_{i}(x)$ have been drawn from the same distribution. We calculate the overlap of the two distributions, denoted as

$P\left(f_{i}>g_{i}\right)=\int_{-\infty}^{\infty} \mathrm{d} x f_{i}(x) \int_{x}^{\infty} \mathrm{d} x^{\prime} g_{i}\left(x^{\prime}\right)$.

The two-sided $p$ value for the null hypothesis is then

$p_{i}=\min \left\{P\left(f_{i}>g_{i}\right), 1-P\left(f_{i}>g_{i}\right)\right\}$.

The $p$ value is calculated independently at each grid point.

To estimate the combined statistical significance in the multi-model ensemble, the $p$ values for each ensemble member are combined according to Fisher's method (Fisher, 1925). This method assumes that the same hypothesis test 
Table 4. Change in CDD, FD and SU for the 2040-2069 period with respect to the CTL period.

\begin{tabular}{|c|c|c|c|c|c|c|c|c|c|c|c|c|}
\hline & \multicolumn{4}{|c|}{ CDD (days $\left.\mathrm{yr}^{-1}\right)$} & \multicolumn{4}{|c|}{ FD (days yr $\left.{ }^{-1}\right)$} & \multicolumn{4}{|c|}{$\mathrm{SU}\left(\right.$ days $_{\mathrm{yr}} \mathrm{r}^{-1}$ ) } \\
\hline & Global & Land & Ocean & Tropical & Global & Land & Ocean & Tropical & Global & Land & Ocean & Tropical \\
\hline $\mathrm{RCP} 4.5$ & 0.15 & 0.31 & 0.08 & 0.48 & -3.03 & -4.91 & -2.24 & -0.26 & 11.51 & 9.68 & 12.28 & 19.13 \\
\hline SALT & -0.04 & -0.29 & 0.07 & -0.05 & -1.69 & -2.52 & -1.34 & -0.14 & 3.41 & 4.35 & 3.01 & 4.84 \\
\hline SULF & 0.16 & 0.41 & 0.05 & 0.47 & -1.34 & -1.72 & -1.18 & -0.06 & 4.35 & 3.61 & 4.67 & 7.41 \\
\hline
\end{tabular}

is carried out on $k$ independent data sets (in our case, the different model runs), and yields the test statistic

$$
X=-2 \sum_{i=1}^{k} \ln \left(p_{i}\right),
$$

with $p_{i}$ calculated according to Eq. (2). Under the null hypothesis, this test statistic follows a $\chi^{2}$ distribution with $2 k$ degrees of freedom. The multi-model combined $p$ value is calculated from the $\chi^{2}$ distribution function with $2 k$ degrees of freedom $p_{\chi^{2}}(x ; 2 k)$ as follows:

$p=\int_{X}^{\infty} p_{\chi^{2}}(x ; 2 k) \mathrm{d} x$.

The geographical patterns of the changes in climate that remain despite climate engineering are examined in the following section and the regions where the changes are statistically significant at $95 \%$ are represented by hatches.

\subsection{Percentile-based climate extreme analysis}

The geographical distributions of change in mean, 90th percentile (T90) and 10th percentile (T10) of near-surface temperature 2040 to 2069 with respect to the reference RCP4.5 control period (CTL, 2006 to 2035) are shown in Fig. 1 for RCP4.5 (left column), SALT (middle column) and SULF (right column).

For the mean and extremes simulated for the RCP4.5 scenario, temperatures are warmer almost everywhere in the 2040-2069 period than in the control (Fig. 1), with more warming over land than over ocean (Collins et al., 2013). In both SRM scenarios, for the mean change in temperature, a residual, statistically significant warming is simulated over most regions globally for mean, upper and lower extremes of the temperature distribution. The warming compared to CTL in mean temperatures is larger than $0.5 \mathrm{~K}$ over the high latitudes $\left(60-90^{\circ} \mathrm{N}\right)$ of the Northern Hemisphere. In the SALT experiment, the strong residual warming is extended over the continents to the mid-latitudes. The geographical distributions of the upper percentile (T90) of the two SRM techniques exhibit different warming patterns. The SALT experiment, implemented in the marine tropical oceans, exhibits more uniform warming of $0.5-1 \mathrm{~K}$ over Northern Hemisphere mid- to high latitudes $\left(30-80^{\circ} \mathrm{N}\right)$, emphasising more the local influence of this experiment. Over most of the tropical oceans, changes in temperature in the SALT experiment is close to or even less than zero with respect to CTL.

In SALT, the pattern for the upper-percentile temperature (T90) values are similar to those for the mean values in the Northern Hemisphere. The SULF experiment rather well mitigates the warming of the upper percentile, down to $0.5 \mathrm{~K}$ or less in most areas. This residual warming is still significant. For both SRM methods, for the upper percentile, there is no warming north of $85^{\circ} \mathrm{N}$. In contrast, most of the warming at the Arctic region occurs at the lower tail of the temperature distribution.

At the lower end of the temperature distribution, the 10th percentile increases in both SRM experiments broadly show a distribution of small, positive changes in the tropics, very similar to the mean temperature change patterns. A much stronger increase in the lower percentile of the temperature distribution (T10) is simulated for the Northern Hemisphere high latitudes, continental regions in the northern mid-latitudes and sea-ice regions in the Southern Hemisphere mid-latitudes. Overall, both SRM schemes tend to substantially narrow the temperature distribution in the Arctic. This is very likely due to the fact that both climate engineering schemes are solar radiation management approaches which can only mitigate climate change during the Arctic day (as seen in the upper percentile), while during Arctic night, almost no local mitigation is achieved by construction. The warming in the lower tail of the temperature distribution may have important effects in the Arctic. This aspect of the SRM is more detailed in Sect. 3.5.

Table 2 lists global and regional means and modelensemble mean values of changes in temperature of 2040 to 2069 minus the reference RCP4.5 control period (2006 to 2035). Difference values for throughout the globe (all points, land only and ocean only), the tropics $\left(30^{\circ} \mathrm{N}-30^{\circ} \mathrm{S}\right)$, midlatitudes $\left(30^{\circ}-60^{\circ}\right.$ in both hemispheres) and high latitudes $\left(60^{\circ}-90^{\circ}\right.$ in both hemispheres) are provided. For the SALT experiment, the models simulate a comparatively effective mitigation for the tropics, and generally over ocean, with warmings of 0.17 to $0.24 \mathrm{~K}$ in the mean and an even more 


\section{Change in near surface temperature [(2040-2069) - CTL]}
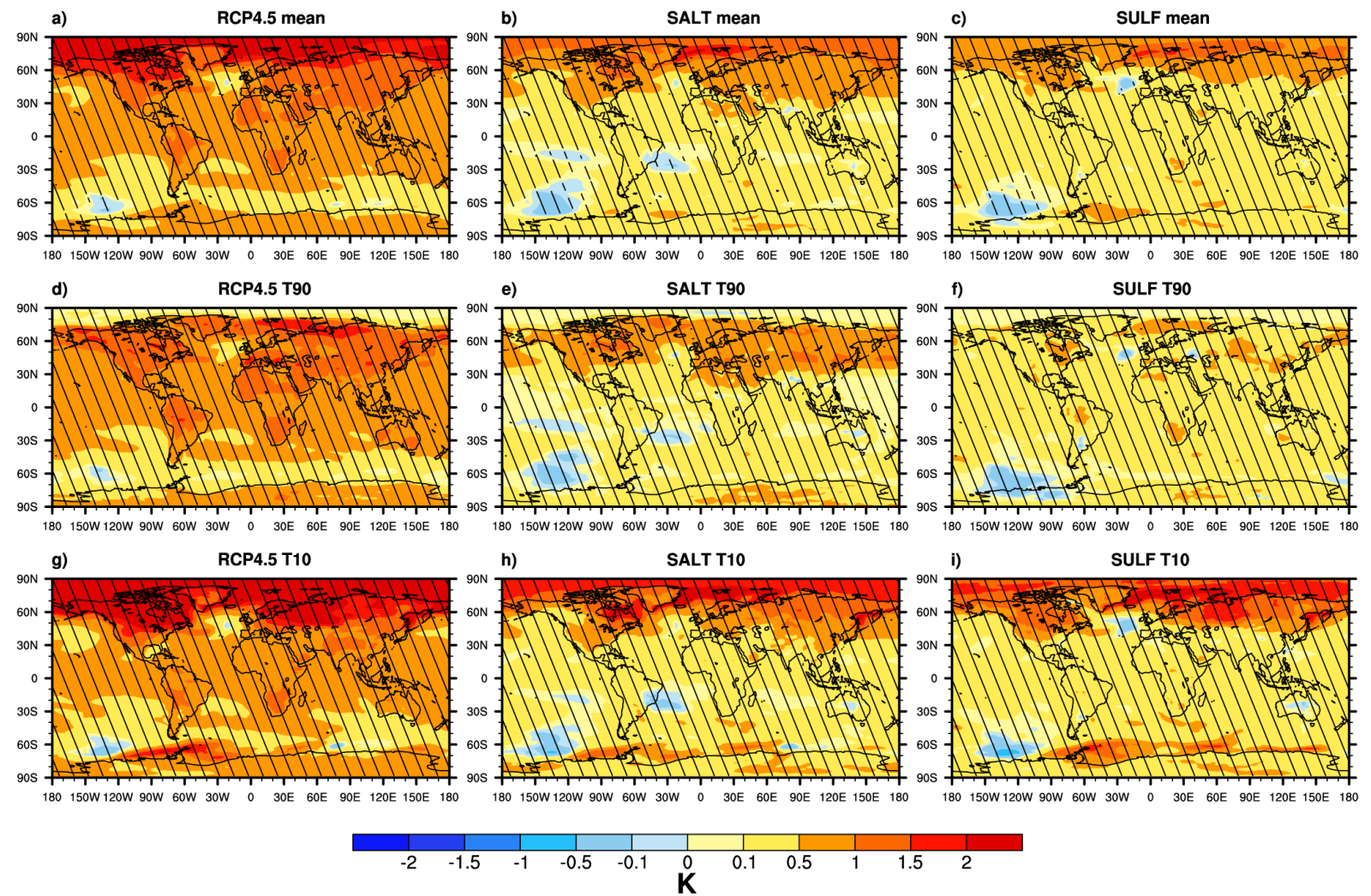

Figure 1. Multi-model mean change in near-surface temperature (K) for RCP4.5 (left column), SALT (middle) and SULF (right column) for 2040-2069 minus the RCP4.5 control period (CTL; 2006-2035). Panels (a) to (c) denote changes in mean values, (d) to (f) same as (a) to (c) but for the 90th percentile and (g) to (i) same as (a) to (c) but for the 10th percentile of the temporal distribution at each model grid point. Hatches denote regions where the changes are $95 \%$ statistically significant.

effective mitigation of the upper extremes. However, over Northern Hemisphere mid- and high latitudes, the SALT experiment leaves a residual warming of 0.57 to $1.01 \mathrm{~K}$, up to double the value simulated by the SULF experiment over the same regions. As discussed earlier for the distributions, irrespective of the SRM technique simulated, warming at the lower tail of the temperature distribution (given by the lower percentile; T10) at Northern Hemisphere high latitudes are much higher than the upper percentiles.

In terms of both the mean and the extremes, the models simulate that the SALT experiment mitigates the warming better in the tropics and most of the Southern Hemisphere, while it simulates a stronger residual warming, compared to the SULF experiment, in the Northern Hemisphere midlatitudes, which may further affect the temperature gradient and circulation from tropics to mid-latitudes (Niemeier et al., 2013). Regarding the lower-percentile (T10) warming, irrespective of the techniques, neither SRM scheme mitigates warming in the Arctic well, nor in some parts of the Southern Ocean region. To get more insight into the warming pat- terns retained during SRM we also investigate the seasonal changes in Sect. 3.5

Changes in mean and the upper-percentile precipitation (P90) are shown in Fig. 2. As documented in earlier studies (e.g. Govindasamy and Caldeira, 2000), the RCP4.5 scenario shows an overall increase in precipitation in the 2040 2069 period compared to the 2006-2035 period, especially in the equatorial region between $5^{\circ} \mathrm{N}$ and $5^{\circ} \mathrm{S}$. The changes in upper-percentile precipitation (P90) in the RCP4.5 scenario are stronger than changes in mean precipitation.

Mean changes in precipitation for the SRM are shown in Fig. $2 \mathrm{~b}$ and $\mathrm{c}$, and the changes in upper-percentile precipitation (P90) in Fig. 2e and f. The SALT experiment differs from the SULF experiment in that the precipitation is influenced by the emission of sea salt impacting cloud droplet number concentrations and subsequently precipitation formation in the clouds via the autoconversion process.

For both mean and extreme precipitation, the SALT experiment shows a rather strong positive anomaly over SouthEast Asia and central Africa. The Indian subcontinent and surrounding land regions are found to experience enhanced 


\section{Change in precipitation [(2040-2069) - CTL]}
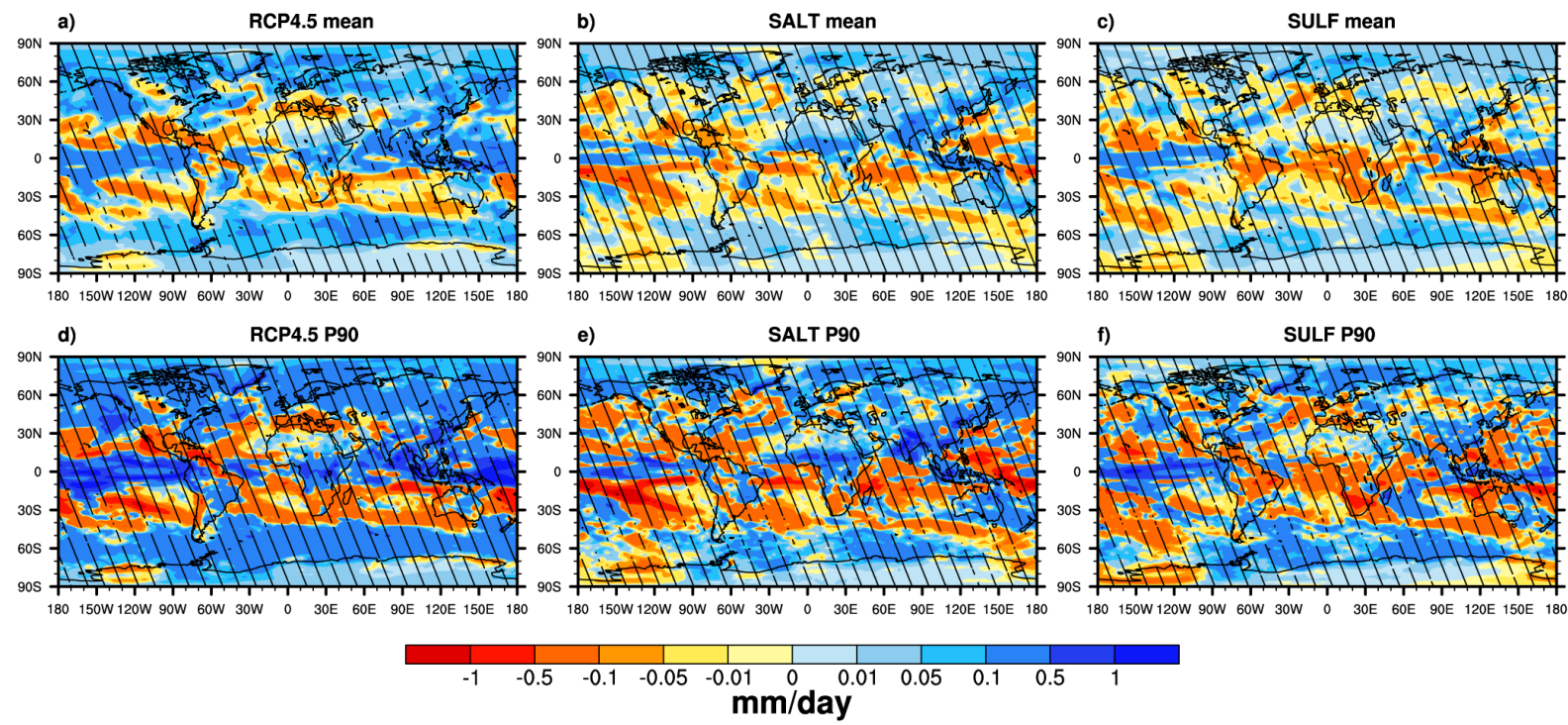

Figure 2. Multi-model mean change in precipitation $\left(\mathrm{mm} \mathrm{day}^{-1}\right.$ ) for RCP4.5 (left column), SALT (middle) and SULF (right column) for the 2040-2069 period minus the RCP4.5 2006-2035 control period (CTL). Panels (a) to (c) denote changes in mean values, (d) to (f) same as (a) to (c) but for the 90th percentile of the temporal distribution at each model grid point. Hatches denote regions where the changes are $95 \%$ statistically significant.

precipitation rates under the SALT experiment. However, in the Amazon rainforest area, the SALT experiment produces a negative anomaly in precipitation, in accordance with the simulation of Jones et al. (2009) on marine cloud brightening. In contrast to land regions, most of the tropical marine regions, including the Intertropical Convergence Zone (ITCZ), Pacific, Atlantic and Indian oceans show a negative anomaly for the SALT experiment. As discussed by Alterskjaer et al. (2013) and Niemeier et al. (2013), in addition to the influence on autoconversion, these changes can be attributed to large-scale dynamics of increasing vertical motion in ITCZ and Walker circulations. This leads to an increase in the convective precipitation over land, compensating for the decrease in precipitation over ocean. Thus over ocean, the SALT experiment is effective in reducing the extreme precipitation increases compared to the CTL period, which are stronger than the RCP4.5 2040s change relative to CTL.

The geographical distributions of the changes in precipitation of mean and upper-percentile precipitation (P90) for the stratospheric climate engineering, SULF are shown in the right column of Fig. 2. In contrast to the SALT experiment, the SULF experiment effectively alleviates the precipitation extreme increases over land in the tropics and Northern Hemisphere mid-latitudes compared to the CTL period, even showing a decrease in extreme precipitation in these areas for P90 precipitation and a highly mitigated value for P99. When averaging globally, these features are prominent with SULF experiment resulting in more positive anomaly in precipita- tion over ocean and vice versa over most of land regions. Hence the changes in precipitation are almost opposite to the SALT experiment, as pointed out in Niemeier et al. (2013) and the paper attributes the changes to the change in Walker circulation.

Mean changes of precipitation for the 2040 to 2069 period with respect to the CTL period are given in Table 3. On global average, mean precipitation and 90th percentile are simulated to be well mitigated by both schemes, while the 99th percentile is still mitigated in its increase. Over land, the residual increase in the upper-percentile precipitation (P99) simulated for the SULF scenario is $0.172 \mathrm{~mm} \mathrm{day}^{-1}$. For the SALT experiment, $0.359 \mathrm{~mm} \mathrm{day}^{-1}$ increases are simulated, which is $50 \%$ less than the RCP4.5 scenario. Over ocean, the SULF experiment shows the same changes as RCP4.5 though less in magnitude. In the SALT experiment, the mean and 90th percentile precipitation is simulated to even decrease, while the 99th percentile is well mitigated in its increase.

In Fig. 3 the precipitation changes as simulated by the individual models are shown. In the SULF scenario, the tendency of all models to simulate moister equatorial tropics (ITCZ) and dryer subtropics is even more evident than for the ensemble mean. The signals are similar between mean and upper percentile (P90), but stronger for the upper percentile. In the SALT experiment, all models widely agree on reduced extreme precipitation over tropical marine regions and moister continents, and this feature is more prominent in SALT compared to the SULF experiment. 


\section{Change in precipitation [(2040-2069) - CTL]}
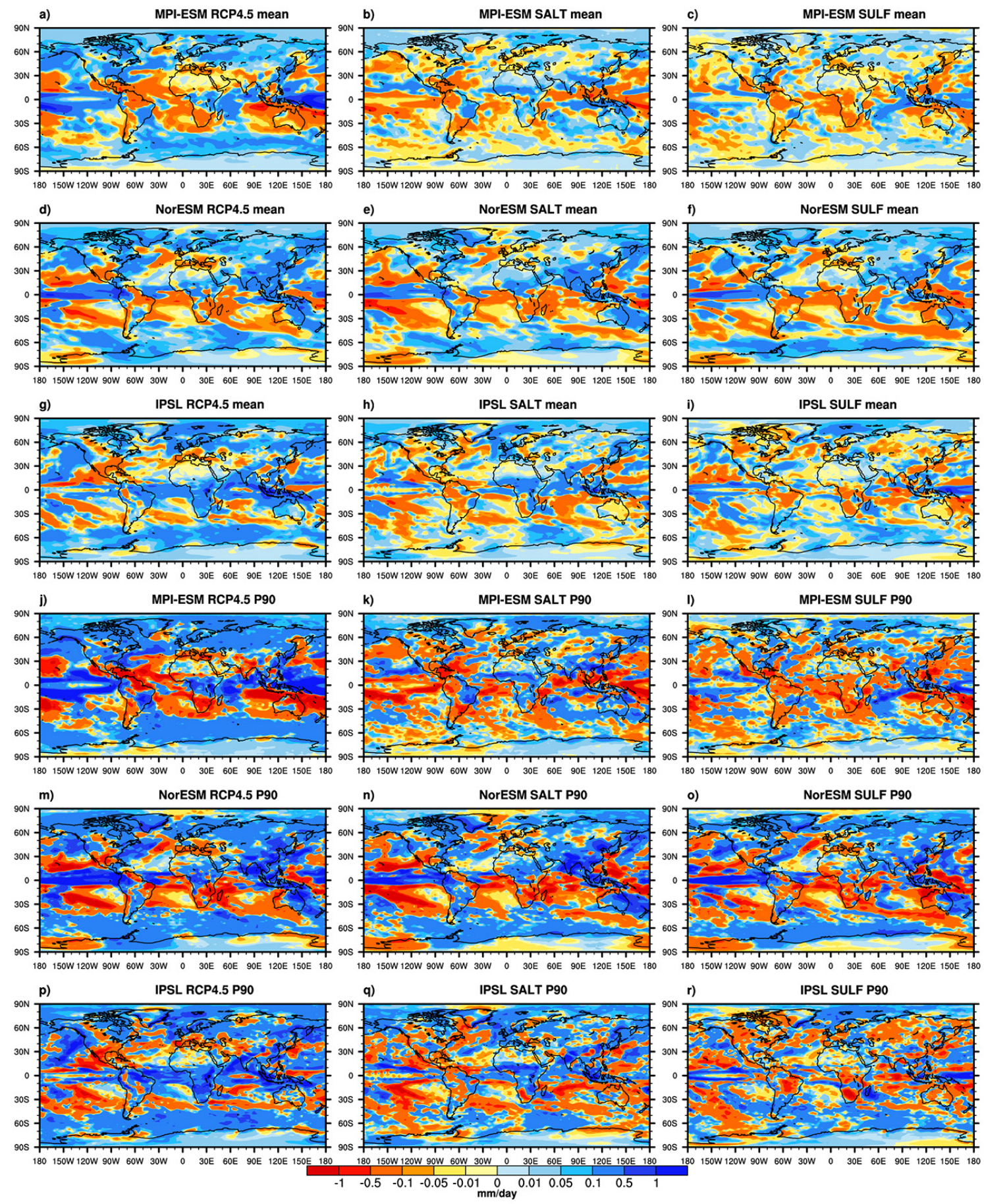

Figure 3. Change in precipitation $\left(\mathrm{mm} \mathrm{day}^{-1}\right)$ for three scenarios RCP4.5, SALT and SULF and three models MPI-ESM, NorESM, IPSL for mean (first three rows) and P90 (last three rows) for the 2040-2069 period minus the RCP4.5 2006-2035 control period (CTL). 


\section{Change in Consecutive Dry Days [(2040-2069) - CTL]}
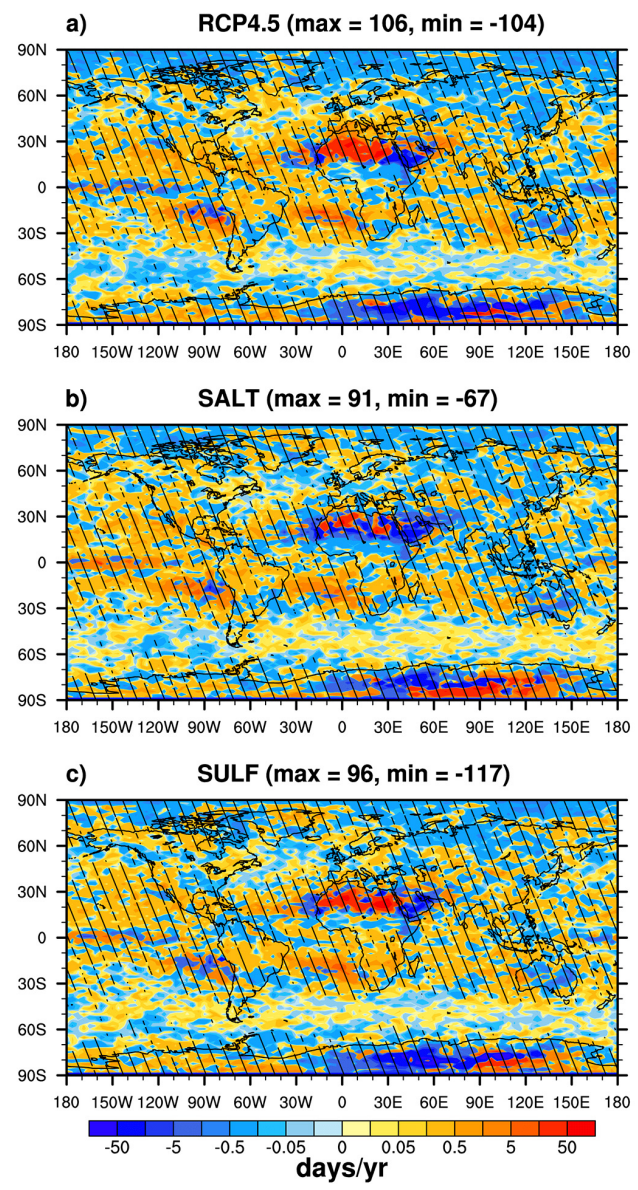

Figure 4. Multimodel mean of change in consecutive dry days RCP4.5 (top panel), SALT (middle) and SULF (bottom panel) for the 2040-2069 period minus the RCP4.5 2006-2035 control period (CTL) period. Hatches denote regions where the changes are $95 \%$ statistically significant.

\subsection{Changes in dry spells}

Dry spells are defined as the largest number of consecutive days (CDD, Table 1) in the analysed period in which precipitation is less than $1 \mathrm{~mm}^{-1 a y}{ }^{-1}$. In Fig. 4 , changes in CDD, in units of days per year, for RCP4.5, SALT and SULF are shown for the 2040-2069 in comparison to the RCP4.5 2006-2035 control period.

In the SALT experiment, shorter dry periods are simulated, especially over the land regions. This could be because in SALT the precipitation has been shifted onto land. Australia, most of Africa and most of Asia show a decrease by approximately $2-5$ days $\mathrm{yr}^{-1}$. Over the Arabian peninsula, the decrease in CDD is up to 10 days $\mathrm{yr}^{-1}$. There are few regions where CDD increases in the SALT experiment, mostly over parts of northern Africa including Libya and Algeria. Overall the effect of SALT is most pronounced over global conti- nents with a reduction of 0.29 days $\mathrm{yr}^{-1}$. Hence, also in the global average values is the overall increase (over continents) and decrease (over ocean) in mean and extreme precipitation (discussed earlier) reflected in the CDD values.

Similar to the result for the SALT experiment, in general, CDD for SULF also seems to decrease where there is increase in precipitation intensity and vice versa. Global mean values of CDD for land only and ocean only also supports this, with more CDD over land and less over ocean with values of 0.41 and 0.05 days $\mathrm{yr}^{-1}$ respectively.

\subsection{Changes cold and hot day frequency of occurrence}

The cold day frequency of occurrence is quantified here as the number of frost days, defined as days per year when the minimum temperature (TN) is less than $0^{\circ} \mathrm{C}$. In RCP4.5, FD is reduced in the mid- to high latitudes, especially of the Northern Hemisphere, by up to 1 month per year, and widespread by 5 or more days per year over all extratropical continental areas of the Northern Hemisphere (Fig. 5), with a global mean value of -3.03 days $\mathrm{yr}^{-1}$ (Table 4 ).

Globally there are fewer frost days under both SRM scenarios compared to CTL period with mean changes of -1.70 and -1.34 days $\mathrm{yr}^{-1}$ for the SALT and SULF experiment respectively (Table 4).

RCP4.5 scenario shows very few regions of increase in frost days. In comparison to RCP4.5, the SRM scenarios maintain more frost days over NH land. However, a strong reduction in the frequency of occurrence of FD is simulated for both SULF and SALT, with patterns very similar to the simulated increase in the RCP4.5 scenario. It may be concluded that the warming, especially at the lower end of the temperature distributions, which is not offset by the SRM scenarios (Sect. 3.2), is sufficiently strong. Hence, it reduces the frequency at which the freezing threshold is reached and subsequently FD are reduced. For all regions, the SULF experiment is simulated to be more effective in mitigating the decrease in frost days, possibly because the forcing is applied globally, and is more effective towards higher latitudes than SALT.

The frequency of occurrence of hot days can be quantified as the number of summer days (SU), defined as the total number of days per year in which TX is greater than $25^{\circ} \mathrm{C}$. Figure 6 shows the yearly change in SU for the 2040-2069 period vs. the CTL period. As expected, RCP4.5 shows an increase in SU. This is most pronounced in the subtropics with increases by up to more than 1 month per year, but it is widespread over low- to mid-latitude continents (Yunyun et al., 2014). In the tropics the maximum increase of 86 days $\mathrm{yr}^{-1}$ corresponds to an entire season more of $\mathrm{SU}$, and the average increase is as much as 11 days $\mathrm{yr}^{-1}$ (Table 4). This strong increase over the tropics is well reduced by the SALT scenario; however, the still substantial increase of 10 20 days $\mathrm{yr}^{-1}$ over North America and Eurasia is only slightly offset. In contrast, the extratropical changes in SU are effec- 


\section{Change in frost days [(2040-2069) - CTL]}
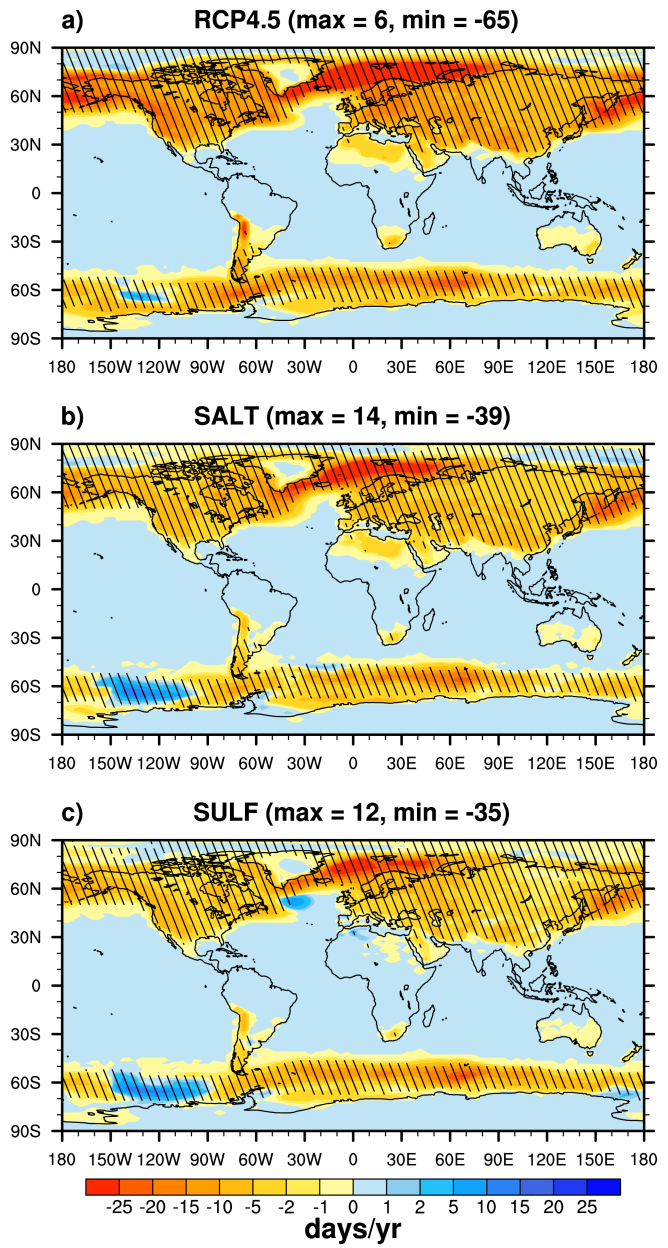

Figure 5. As Fig. 4, but for the mean change in frost days.

tively reduced by the globally applied SULF scheme, where, in turn, still substantial increases in SU over the tropics (up to 30 days year ${ }^{-1}$ ) are simulated. Looking at the global mean values and also ocean and tropics separately, it is clear that the increases in the occurrence of summer days are more effectively reduced in the SALT experiment, which is not surprising considering this is the region of the forcing.

\subsection{Seasonal changes in extremes}

Temperature and precipitation extreme events depend a lot on the seasonal variations. Hence studying the annual changes is not enough to explain the extreme event analysis. So we also analyse the change in extreme events based on two different seasons, namely DJF and JJA. This analysis is done for the percentile-based method, i.e. upper percentile (90th percentile) and lower percentile (10th percentile).

Zonal mean changes in the mean, upper percentile (T90) and lower percentile (T10) temperature for annual, DJF and

\section{Change in summer days [(2040-2069) - CTL]}
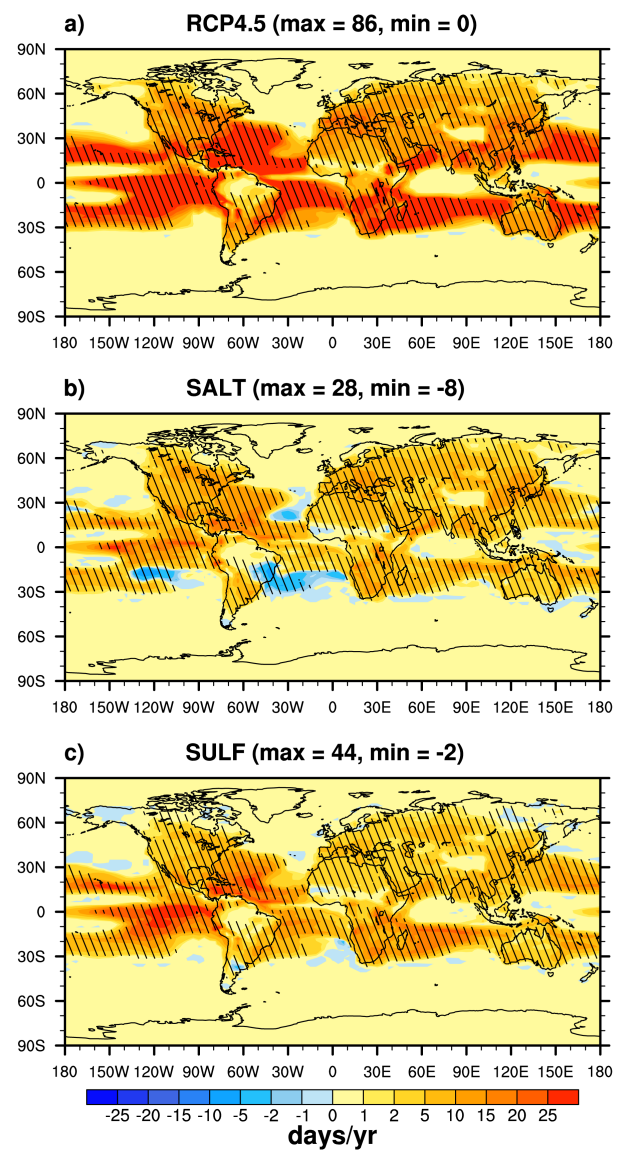

Figure 6. As Fig. 4, but for the mean change in summer days.

JJA periods are shown in Fig. 7. During DJF, there is noticeable warming over the Northern Hemisphere high latitudes for the upper percentile (T90) for both SRM methods. This signal was completely absent in the annual change analysis Sect. 3.2. The SRM techniques are ineffective during winter over the high latitudes. Therefore, even with SRM implementation, warming in the Northern Hemisphere polar regions still persists. This result shows one of the major caveats of the SRM techniques. The change in upper percentile (T90) for JJA is similar to the annual change in temperature. Lower-percentile (T10) analysis for DJF seasonal temperature also exhibits profound warming over the Northern Hemisphere, higher in magnitude and spatial extent than the upper-percentile (T90) warming. The warming pattern in lower percentile is mostly similar to the annual change analysis. The warming in the lower tail of the temperature distribution has implications for permafrost and ice melting and sea level rise. These are some of the major issues of anthropogenic climate change that are not inherently addressed by the SRM techniques. 
Temperature zonal mean [(2040 to 2069)-CTL]
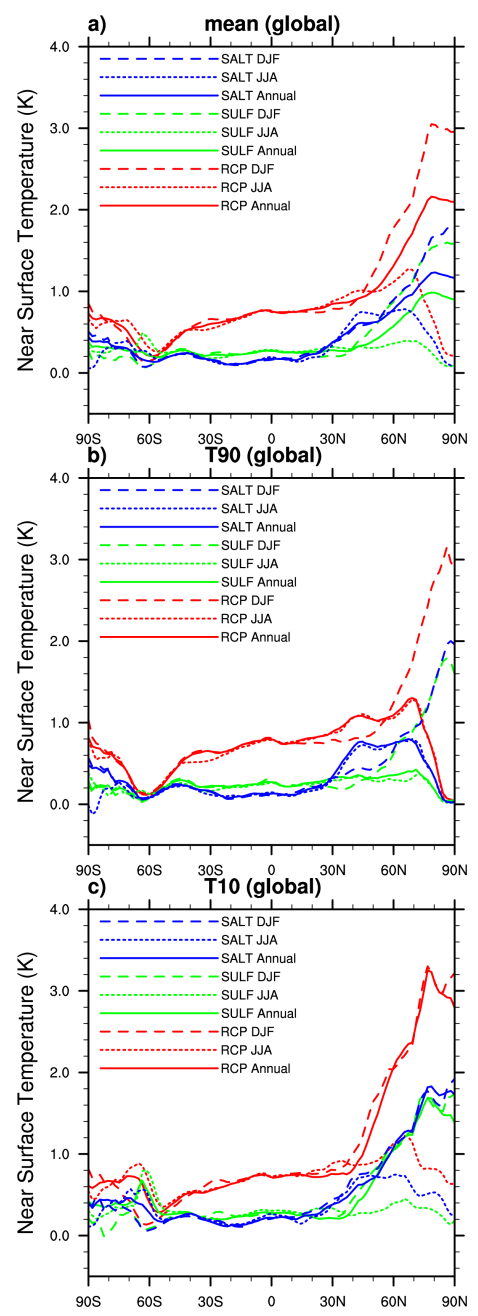

Figure 7. Multi-model zonal mean changes in temperature (K) of RCP4.5 (red), SALT (blue) and SULF (green) for the 2040-2069 period minus the RCP4.5 2006-2035 control period (CTL) for annual mean, DJF and JJA. The top panel shows changes in mean values, middle panel for the 90th percentile values and bottom panel for the 10th percentile values.

However, for JJA lower-percentile temperature (T10) there is much less warming over the Northern Hemisphere high latitudes, indicating the effectiveness of SRM during summer. Even though there is less warming in the Arctic, there is still residual warming of 0.5 to $1 \mathrm{~K}$ over the Northern Hemisphere mid-latitudes in the SALT experiment. Since JJA corresponds to winter in the Southern Hemisphere, there is a net warming in the lower percentile (T10) in the Southern Hemisphere.

In conclusion, irrespective of both SRM techniques, there is net warming at the lower tail of the temperature distribution at high latitudes during winter. The extent of warming is more in the SALT experiment compared to the SULF ex- periment. Annual changes in the upper percentile (T90) is essentially that of JJA and lower percentile (T10) is that of DJF.

Precipitation changes are highly dependent on seasons, and Fig. 8 shows the zonal mean changes in precipitation for annual, DJF and JJA periods. Since precipitation patterns are different over land and ocean, zonal mean curves for landonly (top row) and ocean-only (bottom row) points are shown separately in Fig. 8. For JJA, which corresponds to the monsoon season over the Northern Hemisphere, SALT leads to an increase in extreme precipitation compared to the CTL scenario. DJF seasonal precipitation mostly behaves similar to the annual mean. In general, for both seasons, similar to annual mean precipitation, seasonal precipitation over land is better treated in the SULF experiment and over ocean in the SALT experiment.

\subsection{Termination effect}

The termination effects of the SULF and SALT experiments are investigated for both temperature and precipitation and are shown in Figs. 9 and 10. We only consider the annual changes in this section and the values are summarised in Table 5 .

As expected, the termination of SRM leads to a rapid net global warming. When following the mean temperature of RCP4.5 scenario in the 2070-2089 vs. the 2050-2069 period, a gradual warming is simulated which is stronger for the average temperatures in the northern polar and mid-latitude regions than the global average of $+0.30 \mathrm{~K}$. T90 temperatures rise at a slower rate than the average ones.

The termination of the SRM leads to strong warming of average and extreme temperatures for both schemes, with slightly larger values for the SULF simulations. For both methods, changes are stronger over land. For both SRM schemes, mean values rise the most in the northern polar regions, while T90 values increase more at mid- and low latitudes over land, with only moderate warming in the polar regions. The global mean values of the temperature changes for the SALT scenario for mean, T90 and T99 are $+0.59,+0.59$ and $+0.65 \mathrm{~K}$, respectively. In the SULF scenario, simulated patterns are similar to SALT, but stronger. The termination of the SULF leads to stronger changes in extreme temperatures also in the mid-latitude and polar regions, compared to the SALT method. The global mean change for temperature extremes over land for SULF is $+0.84 \mathrm{~K}$. In lower percentiles (T10) due to termination, temperature rises much faster than the mean and upper percentile (T90) in both SRM schemes. Particularly strong warming is simulated over the northern high latitudes and some regions of the Southern Ocean.

Similar analysis is carried out for precipitation as well. Termination of SALT leads to strong increases of precipitation over most regions. However, the models simulate reduced precipitation over some subtropical land regions, namely northern Africa, Europe and some regions of 
Table 5. Change in temperature and precipitation for the 2070-2089 period with respect to the 2050-2069 period.

\begin{tabular}{llrrrrrrrr}
\hline & & \multicolumn{3}{c}{ Temperature (in K) } & \multicolumn{4}{c}{ Precipitation (in mm day ${ }^{-1}$ ) } \\
& & Global & Land & Ocean & Tropical & Global & Land & Ocean & Tropical \\
\hline \multirow{3}{*}{ RCP4.5 } & Mean & 0.30 & 0.39 & 0.26 & 0.26 & 0.021 & 0.153 & 0.023 & 0.021 \\
& T90/P90 & 0.29 & 0.37 & 0.25 & 0.30 & 0.069 & 0.542 & 0.075 & 0.081 \\
& T99/P99 & 0.30 & 0.38 & 0.27 & 0.31 & 0.415 & 0.194 & 0.508 & 0.601 \\
& T10 & 0.34 & 0.48 & 0.29 & 0.22 & - & - & - & - \\
& T1 & 0.41 & 0.62 & 0.32 & 0.20 & - & - & - & - \\
\hline \multirow{5}{*}{ SALT } & Mean & 0.59 & 0.75 & 0.53 & 0.64 & 0.054 & 0.021 & 0.067 & 0.071 \\
& T90/P90 & 0.59 & 0.73 & 0.53 & 0.73 & 0.152 & 0.070 & 0.187 & 0.207 \\
& T99/P99 & 0.64 & 0.81 & 0.58 & 0.81 & 0.771 & 0.461 & 0.902 & 1.001 \\
& T10 & 0.61 & 0.80 & 0.53 & 0.56 & - & - & - & - \\
& T1 & 0.62 & 0.80 & 0.54 & 0.50 & - & - & - & - \\
\hline \multirow{5}{*}{ SULF } & Mean & 0.62 & 0.84 & 0.52 & 0.61 & 0.054 & 0.056 & 0.054 & 0.067 \\
& T90/P90 & 0.65 & 0.93 & 0.53 & 0.65 & 0.135 & 0.167 & 0.121 & 0.157 \\
& T99/P99 & 0.70 & 1.02 & 0.57 & 0.72 & 0.678 & 0.561 & 0.727 & 0.850 \\
& T10 & 0.63 & 0.83 & 0.55 & 0.58 & - & - & - & - \\
& T1 & 0.65 & 0.83 & 0.57 & 0.57 & - & - & - & - \\
\hline
\end{tabular}

Table 6. Change in temperature and precipitation of SALT and SULF of the 2040-2069 period minus the corresponding period in the RCP4.5.

\begin{tabular}{lllllllrrr}
\hline & & \multicolumn{3}{c}{ Temperature (in K) } & \multicolumn{4}{c}{ Precipitation (in mm day ${ }^{-1}$ ) } \\
& & Global & Land & Ocean & Tropical & Global & Land & Ocean & Tropical \\
\hline \multirow{5}{*}{ SALT - RCP4.5 } & Mean & -0.46 & -0.58 & -0.41 & -0.55 & -0.045 & -0.009 & -0.061 & -0.062 \\
& T90/P90 & -0.46 & -0.57 & -0.41 & -0.61 & -0.123 & -0.025 & -0.165 & -0.173 \\
& T99/P99 & -0.51 & -0.63 & -0.46 & -0.66 & -0.653 & -0.307 & -0.798 & -0.862 \\
& T10 & -0.47 & -0.63 & -0.40 & -0.49 & - & - & - & - \\
& T1 & -0.47 & -0.61 & -0.41 & -0.45 & - & - & - & - \\
\hline \multirow{5}{*}{ SULF - RCP4.5 } & Mean & -0.47 & -0.66 & -0.39 & -0.48 & -0.046 & -0.045 & -0.046 & -0.059 \\
& T90/P90 & -0.48 & -0.71 & -0.39 & -0.51 & -0.111 & -0.125 & -0.105 & -0.138 \\
& T99/P99 & -0.53 & -0.77 & -0.43 & -0.55 & -0.592 & -0.494 & -0.633 & -0.782 \\
& T10 & -0.47 & -0.66 & -0.39 & -0.45 & - & - & - & - \\
& T1 & -0.48 & -0.68 & -0.39 & -0.44 & - & - & - & - \\
\hline
\end{tabular}

the Indian subcontinent due to the termination effect. The global mean change of precipitation extremes over land is $+0.461 \mathrm{~mm} \mathrm{day}^{-1}$ (P99), half the magnitude over ocean. Tropics experience a large increase in precipitation extremes (P99) with a net value of $+1.001 \mathrm{~mm} \mathrm{day}^{-1}$. Under SULF termination, there is large increase in precipitation over most of the land, mainly in south-east Asia, southern Africa and the Amazon region. Overall the precipitation over land regions is increased by $+0.561 \mathrm{~mm} \mathrm{day}^{-1}$

In conclusion, the termination effect of SULF on temperature is stronger than for the SALT experiment. In the SALT experiment, the termination results in larger precipitation increases over ocean than land. Hence, in general, the termination of the SRM schemes results in a reversal of the patterns simulated to occur during the climate engineering period.

\section{Summary and conclusions}

In this study, the results of simulations with three different Earth system models within the SRM climate engineering model intercomparison studies of IMPLICC and GeoMIP have been analysed with respect to surface air temperature and precipitation and their corresponding extreme indices. Two solar radiation management methods were implemented in these simulations, namely the injection of stratospheric aerosols (SULF) and marine cloud brightening by sea salt injections (SALT). Both solar radiation management climate engineering methods are effective at counteracting mean global warming. However, the extratropics and high latitudes warm up during the climate engineering period in the marine cloud brightening experiment, SALT, where SRM is implemented only in the tropics.

The focus of this study was on the changes in extremes, defined here as the upper percentile (T90/P90) and lower 


\section{Precipitation zonal mean [(2040 to 2069)-CTL]}

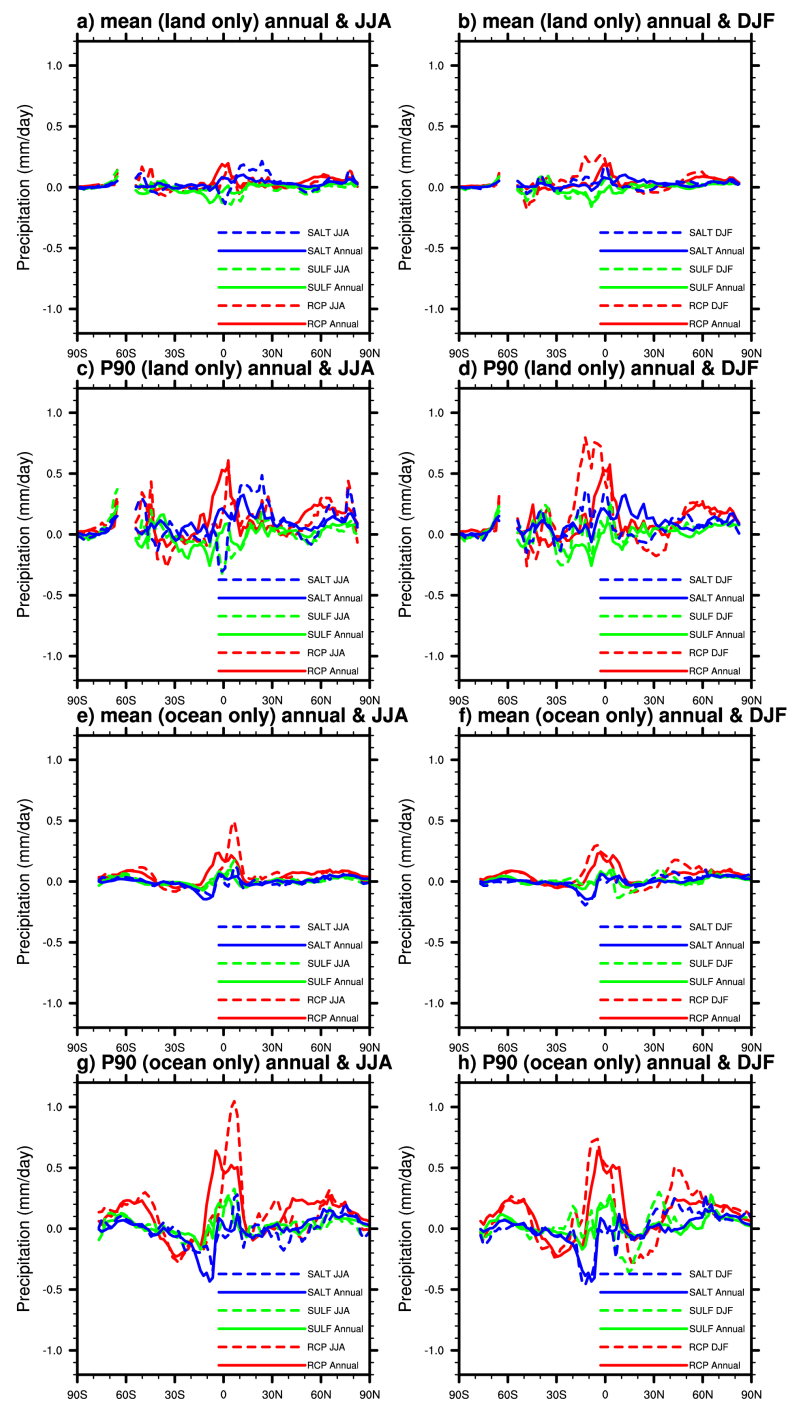

Figure 8. Multi-model zonal mean changes in precipitation $\left(\mathrm{mm} \mathrm{day}^{-1}\right.$ ) of RCP4.5 (red), SALT (blue) and SULF (green) for the 2040-2069 period minus the RCP4.5 2006-2035 control period (CTL) for annual mean, DJF and JJA periods. Left column for JJA and right column for DJF. First two rows show mean and P90 of land only and the bottom two rows show mean and P90 of ocean only points respectively.

percentile (T10/P10) of the 30-year temporal distribution of near-surface temperature and precipitation at each grid point. We also define the temperature and precipitation extremes based on the fixed threshold, namely dry-spell (consecutive dry days), frost-day and summer-day indices.

In the simulations investigated, upper-percentile temperature (T90) shows small positive changes over the tropics except Northern Hemisphere mid- and high latitudes. In Northern Hemisphere mid- and latitudes, warm temperatures (T90) rise less than the mean, but the cold temperatures (T10) much stronger than the mean. This is consistent with the expectation, since SRM is effective only during polar day.

Defining temperature extremes by fixed thresholds, namely frost days as those where the minimum temperature is colder than the freezing point, and summer days as those where the maximum temperature is warmer than $25^{\circ} \mathrm{C}$, it is found that the spatial patterns for the two SRM techniques differ. SULF better reduces the increase in the extratropics while SALT better reduces the increase in the subtropics. Globally, SALT is better in reducing the increase in the summer days compared to SULF. However, frost days are better mitigated in the SULF experiment.

The change in precipitation pattern mostly contrast each other in both SRM techniques compared to the reference CTL period (2006 to 2035). In the tropical marine regions, the SALT scheme leads to an overall reduction in precipitation compared to CTL period. Extreme precipitation increases over land are more effectively reduced in SULF than the SALT experiment. The geographical patterns of the P90 precipitation change show large variability which averages out when considering large regions.

Extremes in temperature and precipitation vary with the season. We thus analysed the percentile extremes separately for the boreal (December-January-February) and austral (June-July-August) winter seasons. The changes in the upper percentile (T90) for the annual distribution represent the changes of the summer seasons (JJA for the Northern Hemisphere and DJF for the Southern Hemisphere), and lower percentile (T10) is that of winter seasons (DJF for Northern Hemisphere and JJA for the Southern Hemisphere). Results indicate that for both SRM techniques there is net warming at the lower tail of the temperature distribution at high latitudes in the boreal and austral winter.

Strong temperature increases are simulated after the cessation of SRM climate engineering. The SULF termination results in a rapid warming of the entire globe, stronger over land in both tropical and extratropical regions than over ocean, and weaker over the Arctic for the 20-year time frame analysed. The SALT termination effect is more confined to the tropics. Also precipitation responds strongly to the termination of SRM climate engineering measures with strong increases over land regions. In conclusion, the termination effect of SULF on temperature is stronger than for the SALT experiment. The SALT experiment termination results in more precipitation increases over ocean than land. Hence, in general, termination of the SRM schemes result in the complete reversal of the patterns observed during the climate engineering period. Extreme values, both for temperature and precipitation, show stronger increases than the mean values for the termination effect.

Our results support some of the previous findings regarding the effectiveness of SRM over the lower latitudes compared to the high latitudes especially in winter (Curry et al., 2014). Our results also reaffirm the fact that the regulation of global mean temperature does not necessarily control the re- 


\section{Change in near surface temperature [Termination]}
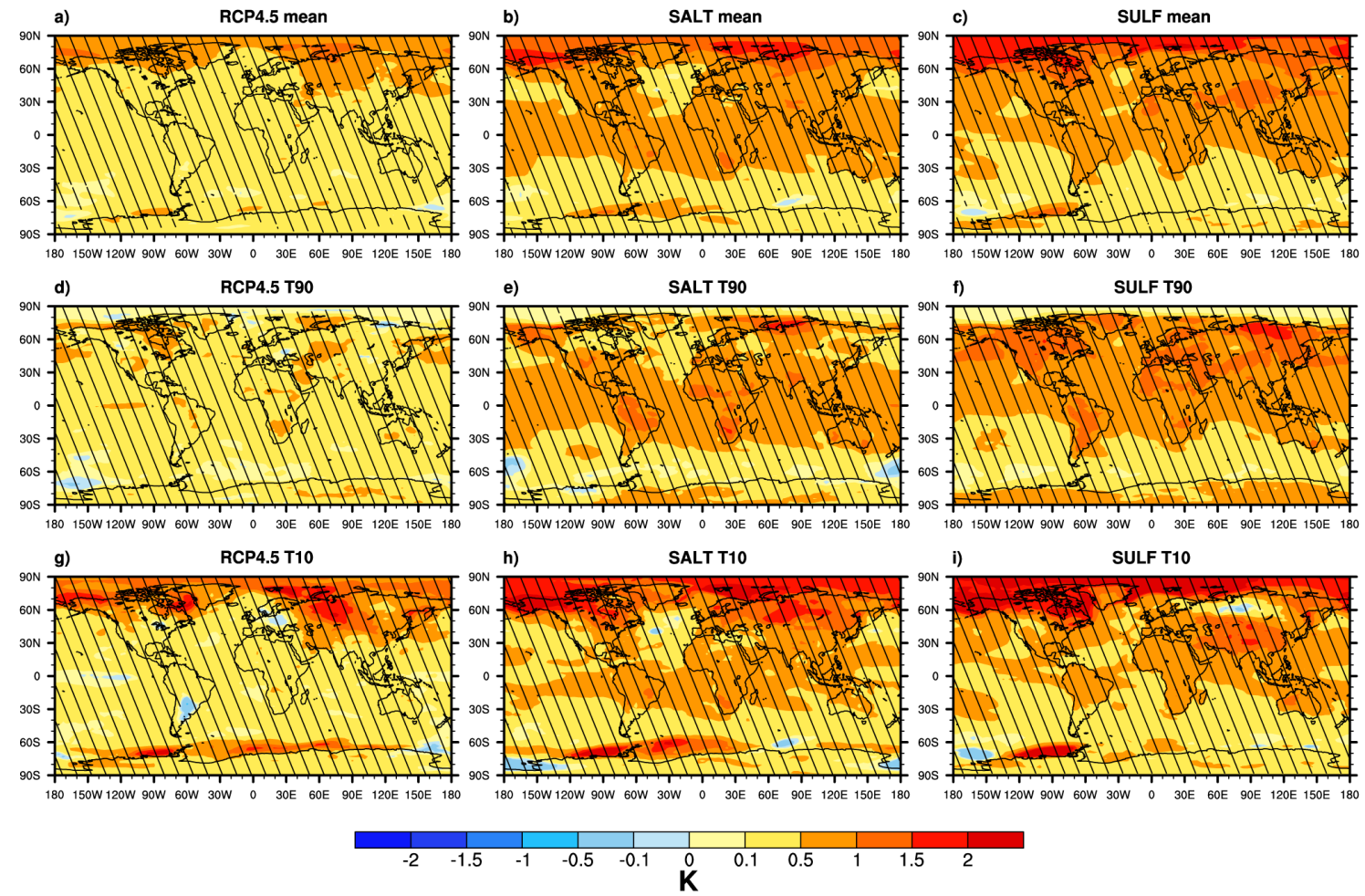

Figure 9. Multi-model mean change in temperature (K) during climate engineering termination period for RCP4.5 (left panel), SALT (middle) and SULF (right panel). Panels (a) to (c) denote changes in mean values, (d) to (f) same as (a) to (c) but for the 90th percentile and (g) to (i) same as (a) to (c) but for the 10th percentile of the temporal distribution at each model grid point. Hatches denote regions where the changes are $95 \%$ statistically significant.

\section{Change in precipitation [Termination]}
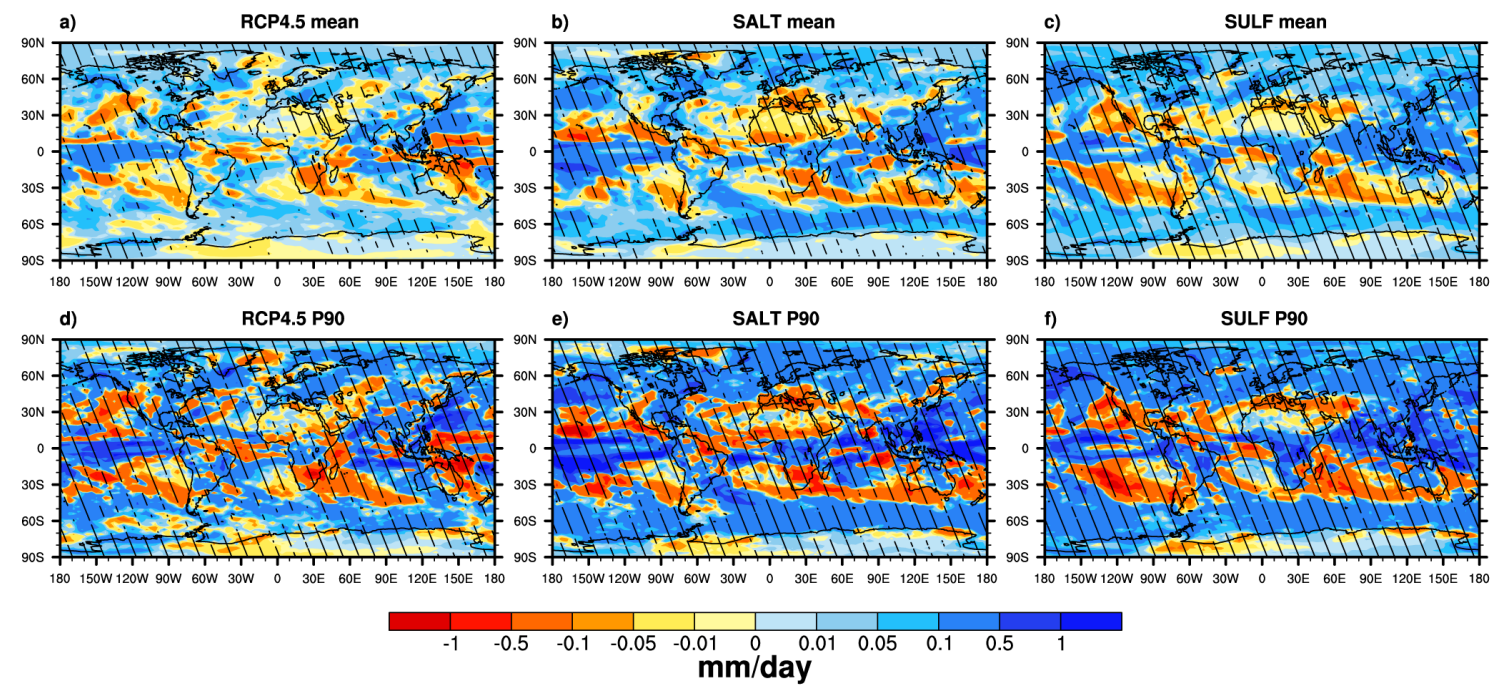

Figure 10. Multi-model mean change in precipitation $\left(\mathrm{mm} \mathrm{day}^{-1}\right)$ during climate engineering termination period for RCP4.5 (left panel), SALT (middle) and SULF (right panel). Panels (a) to (c) denote changes in mean values, (d) to (f) same as (a) to (c) but for the 90 th percentile of the temporal distribution at each model grid point. Hatches denote regions where the changes are $95 \%$ statistically significant. 
gional climate (Ban-Weiss and Caldeira, 2010; Irvine et al., 2010). The SALT experiment results in a large increase in precipitation over land, which reinforces the results from an idealised scenario by Bala et al. (2011). Moist events over land is better mitigated in SULF than in SALT (Niemeier et al., 2013).

Our results show that SALT is more localised and more effective over the tropical regions. Most of the tropical marine regions show small changes in extreme temperature compared to the CTL period. We found that the SULF experiment is effective in mitigating increases in extreme precipitation over land while SALT mitigates these increases over ocean. In terms of the extremes based on threshold values, namely changes in the occurrence of frost days, summer days and length of consecutive dry days, both SRM schemes somewhat alleviate the effects of warming. But globally, the SALT experiment tends to reduce consecutive dry days and also reduce the increase in summer days than the SULF experiment. Globally over land in temperature, the termination due to SULF is greater in magnitude than the corresponding RCP4.5 and SALT scenarios. The warming over the lower tail of temperature distribution due to termination is much higher in magnitude compared to mean and higher temperature. By the time of termination, besides an increase in precipitation over most of the globe, we also found a decrease in precipitation in the SALT experiment over the Indian subcontinent, northern Africa and Europe.

Overall, we conclude that the climate-change-driven increases in the upper extremes of temperature and precipitation are simulated to be rather well mitigated by the two SRM climate engineering methods. However, we also find that the potential to mitigate effects of climate change by means of SRM differs around the globe and seasonally. The increase in the mean temperatures in the Arctic and particularly the increase in the lower temperature percentile in the Arctic winter are not very well dampened. At the same time, it is not easy to locally engineer the climate by SRM methods, as the analysis of the SALT scenario shows. These findings indicate that additional social and political conflicts between regions of the world might occur if it should come to discussions about the eventual implementation of SRM.

\section{The Supplement related to this article is available online at doi:10.5194/acp-15-9593-2015-supplement.}

Acknowledgements. The IMPLICC EU project (grant no FP7ENV-2008-1-226567) and its researchers (Ulrike Niemeier and Hauke Schmidt, Max Planck Institute for Meteorology, Hamburg; Michael Schulz, met.no Oslo; Kari Alterskjær and Jón Egill Kristjánsson, University of Oslo); and the GeoMIP project are acknowledged for conducting the simulations and providing the model output. This study was supported by the German Research
Foundation (Deutsche Forschungsgemeinschaft, DFG) as part of the priority programme (Schwerpunktprogramm 1689 Climate Engineering - Risks, Challenges, Opportunities?), project Learning about cloud brightening under risk and uncertainty: Whether, when and how to do field experiments, GZ QU-311/10-1 and GZ QU 357/3-1. The IPSL-CM5A climate simulations were performed with the HPC resources of CCRT/TGCC/CINES/IDRIS under the allocation 2012-t2012012201 made by GENCI (Grand Equipement National de Calcul Intensif), CEA (Commissariat l'Energie Atomique et aux Energies Alternatives), and CNRS (Centre National de la Recherche Scientifique). Ulrike Niemeier is funded by SPP 1689 project Ceibral. MPI-ESM simulations were preformed on the computers of Deutsches Klimarechenzentrum (DKRZ). Helene Muri is funded by the Norwegian Research Council Project EXPECT (grant 229760/E10) and NorESM1-M computing resources was provided by NOTUR (NN9182K, NN2345K) and NORSTORE (NS9033K, NS2345K). The authors are grateful to Simone Tilmes and two anonymous reviewers for their constructive and helpful comments.

Edited by: L. M. Russel

\section{References}

Alterskjær, K., Kristjánsson, J. E., and Seland, Ø.: Sensitivity to deliberate sea salt seeding of marine clouds - observations and model simulations, Atmos. Chem. Phys., 12, 2795-2807, doi:10.5194/acp-12-2795-2012, 2012.

Alterskjaer, K., Kristjánsson, J. E., Boucher, O., Muri, H., Niemeier, U., Schmidt, H., Schulz, M., and Timmreck, C.: Sea-salt injections into the low-latitude marine boundary layer: The transient response in three Earth system models, J. Geophys. Res.-Atmos., 118, 12195-12206, doi:10.1002/2013JD020432, 2013.

Bala, G., Caldeira, K., Nemani, R., Cao, L., Ban-Weiss, G., and Shin, H. J.: Albedo enhancement of marine clouds to counteract global warming: Impacts on the hydrological cycle, Clim. Dynam., 37, 915-931, doi:10.1007/s00382-010-0868-1, 2011.

Ban-Weiss, G. a. and Caldeira, K.: Geoengineering as an optimization problem, Environ. Res. Lett., 5, 034009, doi:10.1088/17489326/5/3/034009, 2010.

Bentsen, M., Bethke, I., Debernard, J. B., Iversen, T., Kirkevåg, A., Seland, Ø., Drange, H., Roelandt, C., Seierstad, I. A., Hoose, C., and Kristjánsson, J. E.: The Norwegian Earth System Model, NorESM1-M - Part 1: Description and basic evaluation of the physical climate, Geosci. Model Dev., 6, 687-720, doi:10.5194/gmd-6-687-2013, 2013.

Collins, M., Knutti, R., Arblaster, J., Dufresne, J.-L., Fichefet, T., Friedlingstein, P., Gao, X., Gutowski, W., Johns, T., Krinner, G., Shongwe, M., Tebaldi, C., Weaver, A., and Wehner, M.: Long-term Climate Change: Projections, Commitments and Irreversibility, in: Climate Change 2013: The Physical Science Basis. Contribution of Working Group I to the Fifth Assessment Report of the Intergovernmental Panel on Climate Change, edited by: Stocker, T. F., Qin, D., Plattner, G.-K., Tignor, M., Allen, S. K., Boschung, J., Nauels, A., Xia, Y., Bex, V., and Midgley, P. M., Cambridge University Press, Cambridge, United Kingdom and New York, NY, USA, 1031, 2013. 
Conover, W. J.: Practical nonparametric statistics, John Wiley and Sons, New York, 2 edn., 1980.

Crutzen, P. J.: Albedo Enhancement by Stratospheric Sulfur Injections: A Contribution to Resolve a Policy Dilemma?, Climatic Change, 77, 211-220, doi:10.1007/s 10584-006-9101-y, 2006.

Curry, C. L., Sillmann, J., Bronaugh, D., Alterskjaer, K., Cole, J. N. S., Ji, D., Kravitz, B., Kristjánsson, J. E., Moore, J. C., Muri, H., Niemeier, U., Robock, A., Tilmes, S., and Yang, S.: A multimodel examination of climate extremes in an idealized geoengineering experiment, J. Geophys. Res.-Atmos., 3900-3923, doi:10.1002/2013JD020648, 2014.

Dufresne, J.-L., Foujols, M.-a., Denvil, S., Caubel, a., Marti, O., Aumont, O., Balkanski, Y., Bekki, S., Bellenger, H., Benshila, R., Bony, S., Bopp, L., Braconnot, P., Brockmann, P., Cadule, P., Cheruy, F., Codron, F., Cozic, a., Cugnet, D., Noblet, N., Duvel, J.-P., Ethé, C., Fairhead, L., Fichefet, T., Flavoni, S., Friedlingstein, P., Grandpeix, J.-Y., Guez, L., Guilyardi, E., Hauglustaine, D., Hourdin, F., Idelkadi, a., Ghattas, J., Joussaume, S., Kageyama, M., Krinner, G., Labetoulle, S., Lahellec, a., Lefebvre, M.-P., Lefevre, F., Levy, C., Li, Z. X., Lloyd, J., Lott, F., Madec, G., Mancip, M., Marchand, M., Masson, S., Meurdesoif, Y., Mignot, J., Musat, I., Parouty, S., Polcher, J., Rio, C., Schulz, M., Swingedouw, D., Szopa, S., Talandier, C., Terray, P., Viovy, N., and Vuichard, N.: Climate change projections using the IPSL-CM5 Earth System Model: from CMIP3 to CMIP5, Clim. Dynam., 40, 2123-2165, doi:10.1007/s00382-012-1636-1, 2013.

Efron, B. and Tibshirani, R. J.: An introduction to the bootstrap, Chapman and Hall/CRC, Boca Raton, 1998.

Fisher, R.: Statistical methods for research workers, Oliver and Boyd, Edinburgh, 1925.

Giorgetta, M. a., Jungclaus, J., Reick, C. H., Legutke, S., Bader, J., Böttinger, M., Brovkin, V., Crueger, T., Esch, M., Fieg, K., Glushak, K., Gayler, V., Haak, H., Hollweg, H.-D., Ilyina, T., Kinne, S., Kornblueh, L., Matei, D., Mauritsen, T., Mikolajewicz, U., Mueller, W., Notz, D., Pithan, F., Raddatz, T., Rast, S., Redler, R., Roeckner, E., Schmidt, H., Schnur, R., Segschneider, J., Six, K. D., Stockhause, M., Timmreck, C., Wegner, J., Widmann, H., Wieners, K.-H., Claussen, M., Marotzke, J., and Stevens, B.: Climate and carbon cycle changes from 1850 to 2100 in MPI-ESM simulations for the Coupled Model Intercomparison Project phase 5, J. Adv. Model. Earth Syst., 5, 572-597, doi:10.1002/jame.20038, 2013.

Govindasamy, B. and Caldeira, K.: Geoengineering Earth's radiation balance to mitigate $\mathrm{CO}_{2}$ induced climate change, Geophys. Res. Lett., 27, 2141-2144, 2000.

Irvine, P. J., Ridgwell, A., and Lunt, D. J.: Assessing the regional disparities in geoengineering impacts, Geophys. Res. Lett., 37, 1-6, doi:10.1029/2010GL044447, 2010.

Jones, A., Haywood, J., and Boucher, O.: Climate impacts of geoengineering marine stratocumulus clouds, J. Geophys. Res., 114, D10106, doi:10.1029/2008JD011450, 2009.

Jones, A., Haywood, J., Boucher, O., Kravitz, B., and Robock, A.: Geoengineering by stratospheric $\mathrm{SO}_{2}$ injection: results from the Met Office HadGEM2 climate model and comparison with the Goddard Institute for Space Studies ModelE, Atmos. Chem. Phys., 10, 5999-6006, doi:10.5194/acp-10-5999-2010, 2010.

Jones, A., Haywood, J. M., Alterskjaer, K., Boucher, O., Cole, J. N. S., Curry, C. L., Irvine, P. J., Ji, D., Kravitz, B., Egill Kristjáns- son, J., Moore, J. C., Niemeier, U., Robock, A., Schmidt, H., Singh, B., Tilmes, S., Watanabe, S., and Yoon, J.-H.: The impact of abrupt suspension of solar radiation management (termination effect) in experiment G2 of the Geoengineering Model Intercomparison Project (GeoMIP), J. Geophys. Res.-Atmos., 118, $9743-$ 9752, doi:10.1002/jgrd.50762, 2013.

Kharin, V. V. and Zwiers, F. W.: Estimating Extremes in Transient Climate Change Simulations, J. Climate, 18, 1156-1173, 2005.

Kharin, V. V., Zwiers, F. W., Zhang, X., and Hegerl, G. C.: Changes in Temperature and Precipitation Extremes in the IPCC Ensemble of Global Coupled Model Simulations, J. Climate, 20, 1419 1444, doi:10.1175/JCLI4066.1, 2007.

Kravitz, B., Robock, A., Boucher, O., Schmidt, H., Taylor, K. E., Stenchikov, G., and Schulz, M.: The Geoengineering Model Intercomparison Project (GeoMIP), Atmos. Sci. Lett., 12, 162167, doi:10.1002/asl.316, 2011.

Kravitz, B., Robock, A., Forster, P. M., Haywood, J. M., Lawrence, M. G., and Schmidt, H.: An overview of the Geoengineering Model Intercomparison Project (GeoMIP), J. Geophys. Res.Atmos., 118, 13103-13107, doi:10.1002/2013JD020569, 2013.

Latham, J.: Marine Cloud Brightening, Nature, 347, 339-340, 1990.

Latham, J.: Amelioration of global warming by controlled enhancement of the albedo and longevity of low-level maritime clouds, Atmos. Sci. Lett., 3, 52-58, doi:10.1006/asle.2002.0048, 2002.

Lenton, T. M. and Vaughan, N. E.: The radiative forcing potential of different climate geoengineering options, Atmos. Chem. Phys., 9, 5539-5561, doi:10.5194/acp-9-5539-2009, 2009.

Yunyun, L., Weijing, L., Jinqing, Z., and Zeng-Zhen, H.: Simulation and Projection of the Western Pacific Subtropical High in CMIP5 Models, J. Meteorol. Res., 28, 327-340, doi:10.1007/s13351014-3151-2, 2014.

Muri, H., Niemeier, U., and Kristjánsson, J. E.: Tropical rainforest response to marine sky brightening climate engineering, Geophys. Res. Lett., 42, 2951-2960, doi:10.1002/2015GL063363, 2015.

Niemeier, U. and Timmreck, C.: What is the limit of stratospheric sulfur climate engineering?, Atmos. Chem. Phys. Discuss., 15, 10939-10969, doi:10.5194/acpd-15-10939-2015, 2015.

Niemeier, U., Schmidt, H., and Timmreck, C.: The dependency of geoengineered sulfate aerosol on the emission strategy, Atmos. Sci. Lett., 12, 189-194, doi:10.1002/asl.304, 2011.

Niemeier, U., Schmidt, H., Alterskjaer, K., and Kristjánsson, J. E.: Solar irradiance reduction via climate engineering: Impact of different techniques on the energy balance and the hydrological cycle, J. Geophys. Res.-Atmos., 118, 11,905-11,917, doi:10.1002/2013JD020445, 2013.

Robock, A., Oman, L., and Stenchikov, G. L.: Regional climate responses to geoengineering with tropical and Arctic SO 2 injections, J. Geophys. Res., 113, D16101, doi:10.1029/2008JD010050, 2008.

Robock, A., Marquardt, A., Kravitz, B., and Stenchikov, G.: Benefits, risks, and costs of stratospheric geoengineering, Geophys. Res. Lett., 36, L19703, doi:10.1029/2009GL039209, 2009.

Schmidt, H., Alterskjær, K., Bou Karam, D., Boucher, O., Jones, A., Kristjánsson, J. E., Niemeier, U., Schulz, M., Aaheim, A. Benduhn, F., Lawrence, M., and Timmreck, C.: Solar irradiance reduction to counteract radiative forcing from a quadrupling of $\mathrm{CO}_{2}$ : climate responses simulated by four earth system models, Earth Syst. Dynam., 3, 63-78, doi:10.5194/esd-3-63-2012, 2012. 
Sillmann, J., Kharin, V. V., Zhang, X., Zwiers, F. W., and Bronaugh, D.: Climate extremes indices in the CMIP5 multimodel ensemble: Part 1. Model evaluation in the present climate, J. Geophys. Res.-Atmos., 118, 1716-1733, doi:10.1002/jgrd.50203, 2013.

Taylor, K. E., Stouffer, R. J., and Meehl, G. a.: An Overview of CMIP5 and the Experiment Design, B. Am. Meteorol. Soc., 93, 485-498, doi:10.1175/BAMS-D-11-00094.1, 2012.
Tilmes, S., Fasullo, J., Lamarque, J.-F., Marsh, D. R., Mills, M., Alterskjaer, K., Muri, H., Kristjánsson, J. E., Boucher, O., Schulz, M., Cole, J. N. S., Curry, C. L., Jones, A., Haywood, J., Irvine, P. J., Ji, D., Moore, J. C., Karam, D. B., Kravitz, B., Rasch, P. J., Singh, B., Yoon, J.-H., Niemeier, U., Schmidt, H., Robock, A., Yang, S., and Watanabe, S.: The hydrological impact of geoengineering in the Geoengineering Model Intercomparison Project (GeoMIP), J. Geophys. Res.-Atmos., 118, 11,03611,058, doi:10.1002/jgrd.50868, 2013. 